\title{
Statistical Bias Correction for Predictions of Indian Ocean Dipole Index with Quantile Mapping Approach
}

\author{
Sri Nurdiati ${ }^{1}$, Ardhasena Sopaheluwakan ${ }^{2}$ and Mohamad Khoirun Najib ${ }^{1}$ \\ ${ }^{1}$ Department of Mathematics, IPB University, Jalan Meranti, Dramaga, Bogor, Indonesia \\ ${ }^{2}$ Meteorology, Climatology and Geophysics Agency (BMKG), Jalan Angkasa 1 No.2, Kemayoran, Jakarta, Indonesia \\ \{nurdiati,najib_mathipb\}@apps.ipb.ac.id,ardhasena@bmkg.go.id
}

\begin{abstract}
Keywords: $\quad$ statistical bias correction, quantile mapping, indian ocean dipole
Abstract: The Indian Ocean Dipole (IOD) is a phenomenon of ocean-atmosphere interaction that affects climate conditions in Indonesia. The IOD index shows the difference between the western and eastern Indian Ocean sea surface temperature. The impact of the IOD can increase the risk of forest fires, floods and crop failure. Thus, an IOD index prediction model is needed to anticipate the impact of the IOD. One of prediction models of sea surface temperature is the ECMWF prediction model. However, this prediction model has systematic errors that can be corrected using a quantile mapping approach. This method corrects the systematic error of the ECMWF model by connecting the distribution between the ECMWF model and OISST in a transfer function, such as different of quantile and polynomial function. Based on the results, the linear function has the highest chance to improve the accuracy of the model. Moreover, the result shows that statistical bias correction is a good method to improve the accuracy of the ECMWF model especially in Januari-April and September-December.
\end{abstract}

\section{INTRODUCTION}

Indonesia has two seasons, the dry and rainy seasons. The season comes periodically, but the length of season and amount of rainfall are not same for each year (Fadholi 2013). One of the reasons is Indonesia located between the Pacific and Indian Oceans. So, the season in Indonesia is effected by global factor such as El Nino Southern Oscillation and Indian Ocean Dipole.

Indian Ocean Dipole or IOD is a phenomenon of ocean-atmosphere interaction in the Indian Oceans that can be measured by Dipole Mode Index (DMI). DMI shows the difference between the western and eastern Indian Ocean sea surface temperature. The positive DMI describes that sea surface temperature anomaly of the Western Indian Ocean (Africa) warmer than the Eastern Indian Ocean (Indonesia). Consequently, the wind blows to the Western Indian Ocean, so that rainfall in Indonesia is decreased. Meanwhile, the negative DMI cause rainfall in Indonesia is increased. The impact of the IOD can increase the risk of forest fires, floods and crop failure. Thus, an IOD index prediction model is needed to anticipate the impact of the IOD.
The prediction models for sea surface temperature are available, one of prediction models of sea surface temperature is the European Centre for Medium-Range Weather Forecasts (ECMWF) prediction model. However, this prediction model has systematic errors that can be corrected. The statistical bias correction with a quantile mapping approach can be used to correct the errors.

Many researchers have studied the statistical bias correction method. Some of them are Piani et.al. (2010) who have studied about statistical bias correction for daily precipitation in regional climate models over Europe. Dasanto et.al. (2014) have studied about statistical bias correction with quantile mapping for rainfall data over DAS Citarum Hulu. Misnawati et.al. (2018) who have compared four methods of bias correction to the CHIRPS rainfall data. There are many approaches that can be used, such as multiple regression, quantile mapping, mean ratio, and power regression. This paper study about statistical bias correction for ECMWF prediction models with quantile mapping approach. The expectation of this paper is the accuracy of the corrected ECMWF prediction model is better than the original ECMWF prediction model. 


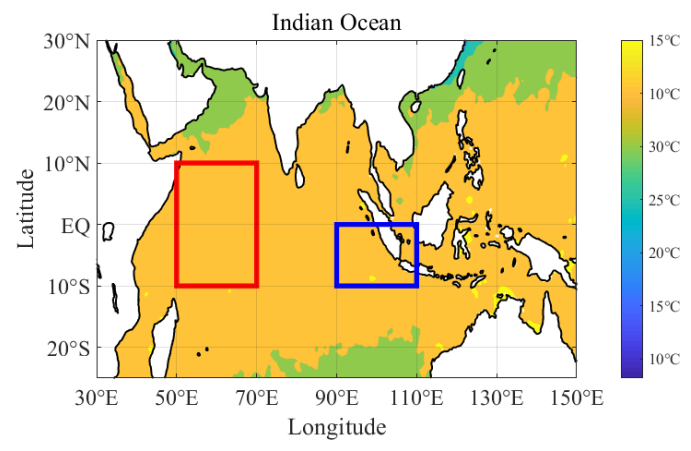

Figure 1: Location of the Western and Eastern Indian Ocean Dipole.

\section{Indian Ocean Dipole.}

Indian Ocean Dipole or IOD is a phenomenon of ocean-atmosphere interaction in the Indian Ocean (Kertayasa et.al.2013). The IOD can be identified using Dipole Mode Index or DMI (Saji et al 1999). DMI shows the difference between the western $\left(50^{\circ} \mathrm{E}-70^{\circ} \mathrm{E}, 10^{\circ} \mathrm{S}-10^{\circ} \mathrm{N}\right)$ and the eastern $\left(90^{\circ} \mathrm{E}-\right.$ $\left.110^{\circ} \mathrm{E}, 10^{\circ} \mathrm{S}-0^{\circ} \mathrm{N}\right)$ Indian Ocean sea surface temperature anomaly. Figure 1 shows location of the western and eastern Indian Ocean Dipole. The positive DMI describes that sea surface temperature anomaly of the Western Indian Ocean (Africa) warmer than the Eastern Indian Ocean (Indonesia). Consequently, the wind blows into the Western Ocean, so that rainfall in Indonesia is decreased. Meanwhile, the negative DMI cause rainfall in Indonesia is increased.

\section{Statistical Bias Correction}

Dasanto (2012) said that statistical bias correction with a quantile mapping approach is a technique to connect the observation and prediction data in a transfer function $y=f(x)$. This function connects the cumulative density function (CDF) of observation and prediction data. The transfer function can be a linear, polynomial, or exponential regression function (Misnawati 2018) or difference between the two CDFs (Leadi 2018).

Misnawati (2018) said that the first step of quantile mapping is to identify the probability density function (PDF) of the observation and prediction data. The second step is to calculate the cumulative distribution function (CDF) by integrating the probability density function (PDF). The third step is to create a transfer function between the CDF of the observation and prediction data.

\section{DATA AND METHOD}

\section{Data}

The observation data is using Optimum Interpolation Sea Surface Temperature or OISST data. OISST has $0.25^{\circ} \times 0.25^{\circ}$ spatial resolution and daily temporal resolution in 1982-2018. Data is released annually with data dimensions of longitude $x$ latitude $\times$ days for each year in netCDF files. Meanwhile, the prediction data is using European Centre for Medium-Range Weather Forecasts or ECMWF data. ECMWF has $0.25^{\circ} \times 0.25^{\circ}$ spatial resolution and daily temporal resolution in 19822018. Data is released monthly with data dimensions of longitude $\times$ latitude $\times$ number of ensemble $\times$ time for each year in netCDF files. ECMWF data forecasts sea surface temperature for the next 216 days than called lead time (LT). From both data, 1982-2011 data was used as training data to create a transfer function. Meanwhile, 2012-2018 data was used as testing data to test the transfer function.

Methods

\section{Data Extraction}

Before the quantile mapping step, the data is extracted from the grid data form to the time series data form by averaging all the longitude and latitude grids for each day. Next, calculate the difference between the average temperature of the western and eastern Indian Ocean and then save it as $\delta T$. The OISST and ECMWF training data are stored as $\delta T_{o b s}$ and $\delta T_{r e f}$ while the ECMWF testing data are stored as $\delta T_{\text {pred }}$.

2. Identify the Distribution

The first step of quantile mapping is to identify the distribution of $\delta T_{o b s}$ and $\delta T_{r e f}$. Data will be identified using some parametric distributions i.e.

- Extreme Value (EV),

- Generalized Extreme Value (GEV),

- Logistic (LOG),

- Normal (NOR),

- Exponential (EXP),

- Gamma (GAM),

- Inverse Gaussian (ING),

- Log-logistic (LL),

- Lognormal (LN), and

- Weibull (WB).

The distribution is chosen based on several statistical parameter values, i.e. negative of the $\log$ likelihood (NLogL), Kolmogorov-Smirnov error (KSE), coefficient of determination $\left(R^{2}\right)$, chisquare $\left(x^{2}\right)$, and root mean squared error (RMSE). 
3. Bias Identification

The next step is to create a transfer function between the CDF of the $\delta T_{o b s}$ and $\delta T_{\text {ref }}$ data. This paper uses 4 types of transfer functions, i.e.

- Difference Between Two CDFs (dCDF),

- Linear Regression Function (LIN),

- Quadratic Regression Function (QUA), and

- Cubic Regression Function (CUB).

The transfer functions are chosen based on periodic test.

4. Test the Transfer Function using $\delta T_{\text {pred }}$

After the transfer function is obtained, then use the transfer function to correct $\delta T_{\text {pred }}$ data.

5. Evaluate the Corrected Prediction Model

To find out the performance of the transfer function for correcting $\delta T_{\text {pred }}$ data, compare ECMWF data before and after corrected to OISST data. Next, calculate the mean ratio and the standard deviation ratio, i.e.

$$
\begin{gathered}
\text { mean ratio }(r \bar{x})=\frac{\bar{x}_{c o r}-x_{o b s}}{\left|\bar{x}_{\text {mod }}-x_{o b s}\right|} \\
\text { standar deviation ratio }(r \sigma)=\frac{\sigma_{c o r}}{\sigma_{m o d}}
\end{gathered}
$$

where

$\bar{x}_{\text {cor }}$ : mean of PDF model after corrected

$\bar{x}_{\text {mod }}$ : mean of PDF model before corrected

$x_{o b s}$ : mean of PDF observation data
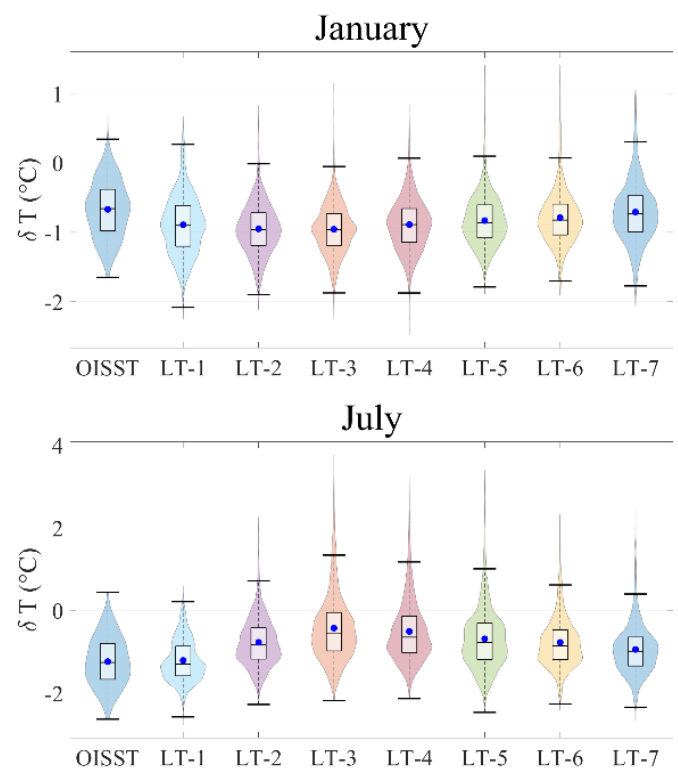

$\sigma_{c o r}:$ standar deviation model after corrected

$\sigma_{\text {mod }}:$ standar deviation model before corrected

\section{RESULTS}

\subsection{Data Overviews}

Using the violin plot, Fig 2 shows four general patterns of $\delta T_{o b s}$ and $\delta T_{\text {ref }}$ data represented by January, April, July and September. Violin plot is a combination of box plot and data distribution function on both sides (Hintze 1998). Based on Figure 2, the first pattern (i.e. in January, February and June) shows that the variance of $\delta T_{o b s}$ and $\delta T_{\text {ref }}$ is not much different. The second pattern (i.e. in March, April, and May) shows that the variance of $\delta T_{\text {ref }}$ is smaller than $\delta T_{\text {obs }}$. The third pattern (i.e. in July, and August) shows that the highest variance occurs at the middle lead time. And the last pattern (i.e. in September until Desember) shows that the highest variance occurs at the higher lead time. If the variance is too high, the precision of the ECMWF prediction will be low. Conversely, if the variance is too small, the prediction is unable to reach the extreme value of the observation. Thus, statistical bias correction is needed to improve accuracy of $\delta T_{\text {ref }}$ data by looking at the tendency of $\delta T_{\text {ref }}$ data against $\delta T_{\text {obs }}$ data.

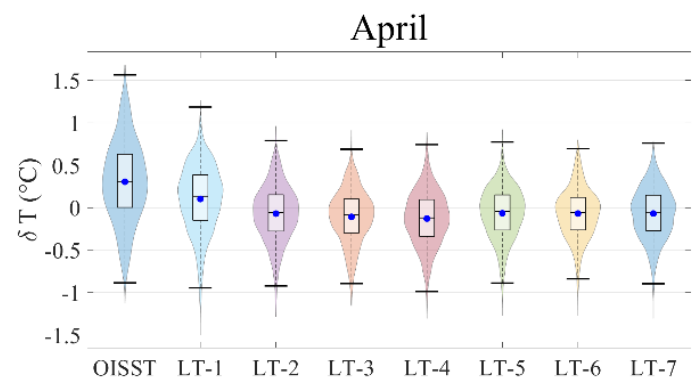

September

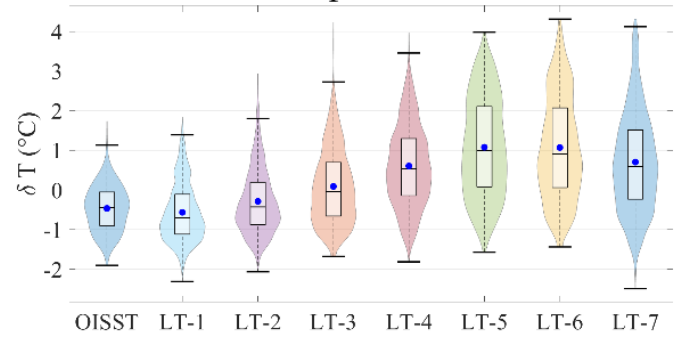

Figure 2: Violin Plot for $\delta T_{o b s}$ and $\delta T_{r e f}$ in January, April, July, and September. 


\subsection{Data Distributions}

Before the identification process begins, the distribution function must be translated because the EXP, GAM, ING, LL, LN, and WB distributions are undefined for $x<0$. The translation is changing PDF from $f(x)$ to $f\left(x-x_{m}\right)$ where the value of $x_{m}$ is smaller than the smallest value of $x$. Furthermore, the value of each distribution parameter will be estimated using the maximum likelihood estimator (MLE) method using MATLAB. For example, Table 1 shows identification results for $\delta T_{o b s}$ in January 19822011. Based on Table 1, the weibull distribution is the chosen distribution because based on statistical parameters the weibull distribution has a better value than the other distribution. The distribution identification process is repeated for $\delta T_{o b s}$ and $\delta T_{\text {ref }}$ every month.

Table 1: Distribution Identification Results for $\delta T_{o b s}$ in January 1982-2011.

\begin{tabular}{|l|r|l|c|c|r|}
\hline Dist & \multicolumn{1}{|c|}{ NLogL } & KSE & $R^{2}$ & $x^{2}$ & RMSE \\
\hline WB & 471.95 & 0.026 & 0.998 & 0.501 & 0.010 \\
\hline GEV & 474.94 & 0.026 & 0.997 & 0.637 & 0.013 \\
\hline NOR & 477.96 & 0.032 & 0.997 & 0.852 & 0.014 \\
\hline GAM & 477.47 & 0.030 & 0.997 & 0.848 & 0.015 \\
\hline LN & 478.00 & 0.030 & 0.997 & 0.882 & 0.015 \\
\hline ING & 477.91 & 0.030 & 0.997 & 0.887 & 0.016 \\
\hline LOG & 500.55 & 0.040 & 0.995 & 1.529 & 0.019 \\
\hline LL & 500.88 & 0.041 & 0.995 & 1.574 & 0.020 \\
\hline EV & 546.49 & 0.065 & 0.982 & 5.205 & 0.036 \\
\hline EXP & 1196.43 & 0.354 & 0.237 & 82.854 & 0.210 \\
\hline
\end{tabular}

\subsection{Transfer Functions}

As explained in the method section, the transfer function to be used is dCDF, LIN, QUA, and CUB. The transfer function can be used for the next step, if the function has an $R^{2}$ value at least $70 \%$ (Dasanto 2014). For example, Table 2 shows the result of creating transfer functions in January at the first lead time. This process is repeated for every month and lead time. The result shows that $R^{2}$ values is more than $80 \%$, so all transfer functions can be used for the next step.

Table 2: The Result of Creating Transfer Function in January at the First Lead Time.

\begin{tabular}{|l|l|}
\hline Function & Formula \\
\hline LIN & $f(x)=0.90 x+0.13$ \\
\hline QUA & $f(x)=0.09 x^{2}+0.76 x+0.09$ \\
\hline CUB & $f(x)=0.05 x^{3}-0.19 x^{2}+0.73 x+0.1$ \\
\hline dCDF & {$[-0.29,-0.22,-0.22,-0.22, \ldots, 0.13]$} \\
\hline
\end{tabular}

The transfer function is selected based on periodic test results. Periodic tests use the transfer function to correct the training data every year in 1982-2011. For example, Table 3 shows the result of periodic testing for transfer function in January at the first lead time. Periodic testing results are expected accuracy and success percentage. Expected accuracy is average accuracy for each years, while success percentage is percentage of transfer function to improve the accuracy for each years. Based on Table 3, the transfer function selected for January at the first lead time is QUA. This process is repeated for every months and lead times. Figure 3 shows the results of selecting the transfer function for every months and lead times. The results show that the linear transfer function is the most chosen transfer function that is up to $43 \%$. Moreover, all selected transfer functions have a percentage of success to improve the accuracy value of at least $50 \%$.

Table 3: The Result of Periodic Testing for Transfer Function in January at the First Lead Time.

\begin{tabular}{|l|r|r|r|r|}
\hline & LIN & QUA & CUB & dCDF \\
\hline $\begin{array}{l}\text { Expected } \\
\text { Acurracy }\end{array}$ & 0.1806 & 0.1790 & 0.1795 & $\mathrm{NaN}$ \\
\hline Percentage & $70 \%$ & $70 \%$ & $70 \%$ & $\mathrm{NaN}$ \\
\hline
\end{tabular}

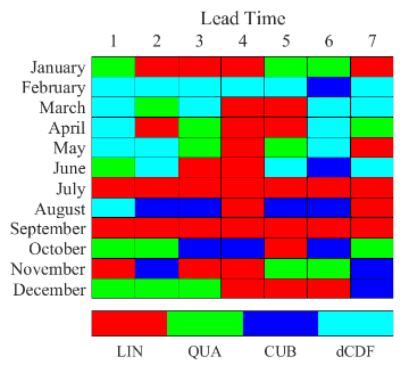

Figure 3: The Results of Selecting The Transfer Function for Every Months and Lead Times. 

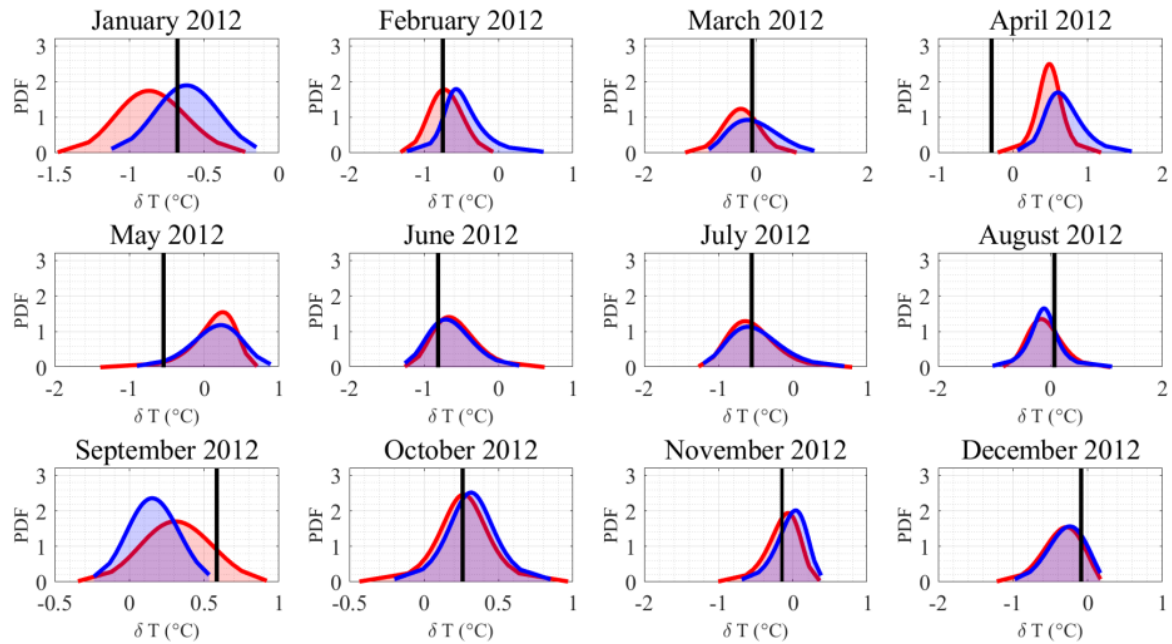

-PDF Model —PDF Corrected Model — Observation Value

Figure 4: The Results of Correcting Data on 2012 at The First Lead Time.

The Result of Correcting Model in 2012-2018 at LT-1

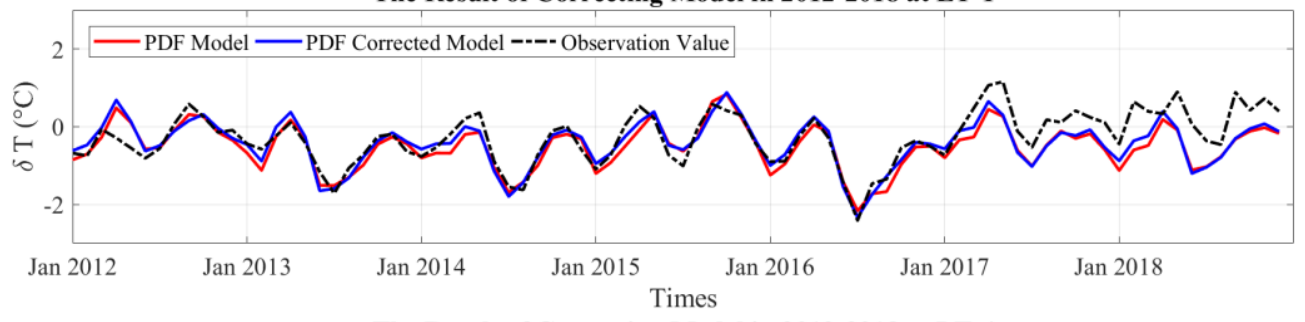

The Result of Correcting Model in 2012-2018 at LT-4

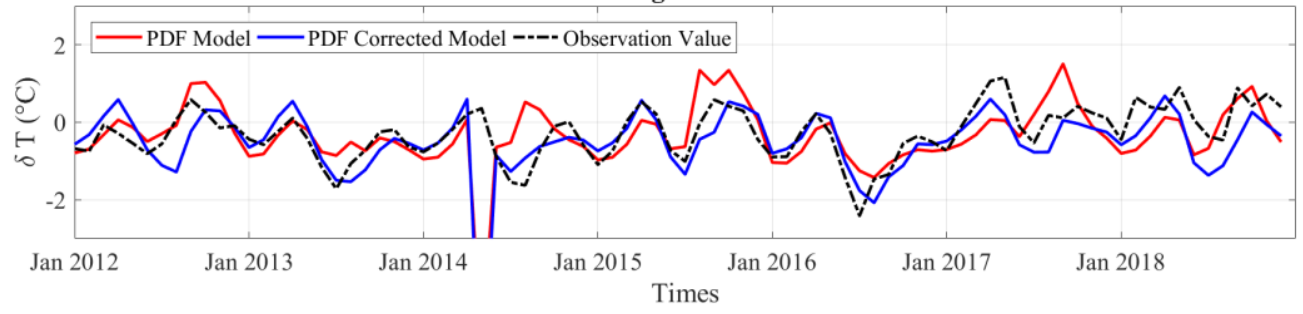

The Result of Correcting Model in 2012-2018 at LT-7

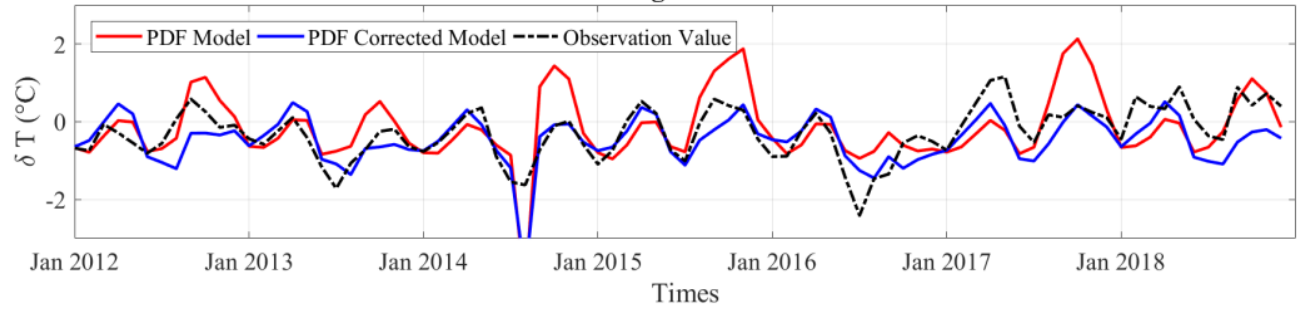

Figure 5: Comparison of PDF Corrected Model Mean in 2012-2018 at 1st, 4th and 7th Lead Time.

\subsection{Testing The Transfer Functions}

The next step, the selected transfer functions are used to correct the testing data $\delta T_{\text {pred }}$ in 2012-2018 for each years. After $\delta T_{\text {pred }}$ has been extracted, the data is identified the distribution and calculated the CDF. Next, correct the CDF using the appropriate transfer functions based on month and lead time. After that, calculated the PDF by differentiating the CDF. For example, Figure 4 shows the results of correcting data in 2012 at the first lead time.

A paper presented as the invited speaker in the $1^{\text {st }}$ International Conference on Science and Mathematics (IMC-SciMath) 2019, Parapat October 9-11, 2019. 
From Figure 4, it can be clearly seen that a correction in January can improve the accuracy of the model because the PDF chart of the corrected model has a closer peak to the observation value. Meanwhile, for another months, it cannot be clearly seen the effect of the statistical correction bias. So, to find out the success of the statistical bias correction process will be evaluated in the next step. Moreover, Fig 5 shows comparison of PDF mean values of the results of correcting data in 2012-2018 at the first, fourth and seventh lead time. The results show that the statistical bias correction has no significant effect at the first lead time. But it has significant effect at the fourth and seventh lead time.

\subsection{Evaluate The Corrected Model}

The evaluation process will use the mean ratio and the standar deviation ratio in equations (1) and (2). The mean ratio compares the accuracy value of the corrected model to the model before it is corrected, while the standard deviation ratio compares the standard deviation of the corrected model to the model before being corrected. There are two criteria of the corrected prediction models can be said to be better than the prediction model before the correction i.e.

1) The mean ratio value is at $(-1,1)$

2) The standar deviation ratio value is at $(0,1)$

Criteria 1) shows that the accuracy of the corrected predictions model is better than the prediction models before being corrected, while criteria 2) shows that the standard deviation of the corrected predictions model is better than the model before correction. Figure 6 shows the distribution of the mean and standar deviation ratio for all months and lead times in 2012-2018. The results showed that $59.52 \%$ of criteria 1 ) and $48.13 \%$ of criteria 2) were reached. Moreover, the figure shows that the statistical bias correction is able to improve the standard deviation especially in January and JulyDecember. However, performance of the statistical bias correction to improving the accuracy can be seen using expected error value in Figure 7.

Based on Figure 7, the result shows that statistical bias correction is a good method to improve the accuracy values of the ECMWF model in January-April and September-December, but the results of the correction in May-August still have a high expected error value, especially in the 4th to 7 th lead time.

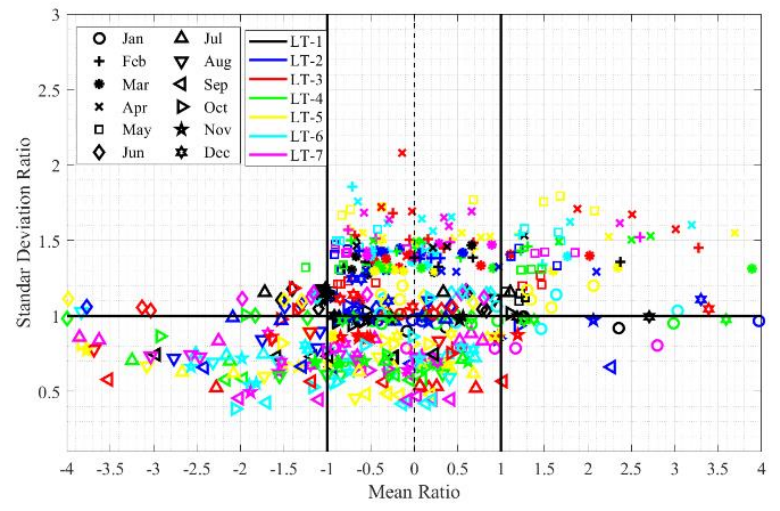

Figure 6: The Distribution of Mean and Standar Deviation Ratio for All Months and Lead Times in 2012-2018.
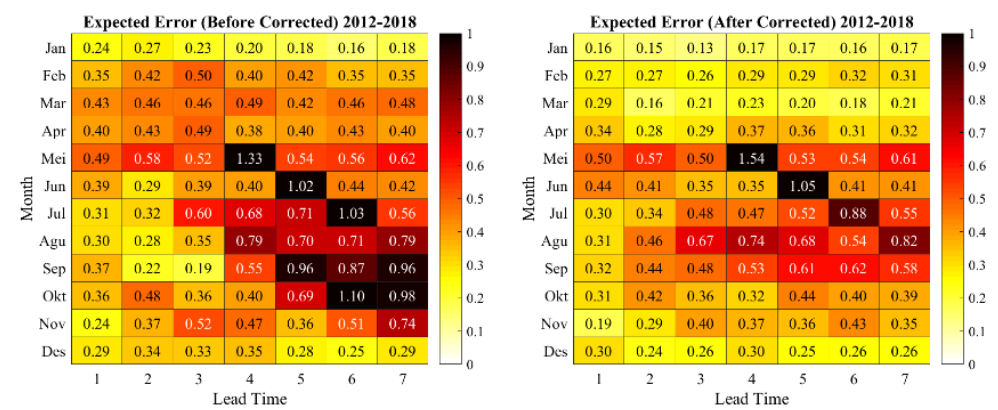

Figure 7: Comparison of the expected error values of the ECMWF model before and after corrected in 2012-2018. 


\section{CONCLUSIONS}

From the transfer functions used, the linear transfer function has the best percentage of success to improve the accuracy value of the ECMWF prediction model. The selected transfer function is a good transfer function because from the results of periodic tests, all selected transfer functions have a percentage of success to improve the accuracy value of at least $50 \%$.

The evaluation results show that the statistical bias correction method can improve the accuracy values of the ECMWF prediction model in JanuaryApril and September-December. This is indicated by the expected error values of the ECMWF model after being corrected which is better than the expected error values of the ECMWF model before being corrected. In addition, the statistical bias correction method can improve the standard deviation values of the ECMWF prediction model in January and July to December. This is indicated by the value of the standard deviation ratio which is in the interval $(0,1)$.

\section{REFERENCES}

Dasanto, B.D., Boer, R., Pramudya, B., Suharnoto, Y., 2014. Evaluasi Curah Hujan TRMM Menggunakan Pendekatan Koreksi Bias Statistik, Jurnal Tanah dan Iklim. 38 (1) : 15-24

Fadholi, A., 2013. Studi Dampak El Nino dan Indian Ocean Dipole (IOD) Terhadap Curah Hujan di Pangkalpinang, Jurnal Ilmu Lingkungan. 11 : 43-50

Hintze, J.L., Nelson, R.D., 1998. Violin Plots: A Box Plot-Density Trace Synergism. The American Statistician 52 (2): 181-184

Kertayasa, I. M., Sukarasa, I.K., Widagda, I.G.A., Hendrawan, I. G., 2013. Pengaruh Indian Ocean Dipole Terhadap Intensitas Hujan Di Benua Maritim Indonesia (BMI) Barat, Buletin Fisika. 14 (1) : 25-30

Lealdi, D., 2018. Pemodelan Koreksi Bias Statistik untuk Prakiraan Curah Hujan untuk Studi Kasus di Pulau Bali [thesis]. Bogor (ID): Institut Pertanian Bogor

Misnawati, Boer, R., June, T., Faqih, A., 2018. Perbandingan Metodologi Koreksi Bias Data Curah Hujan CHIRPS. LIMNOTEK 2018. 25 (1) : $18-29$

Piani C, Harter J O, Coppola E. 2010. Statistical Bias Correction For Daily Precipitation In
Regional Climate Models Over Europe. Theor Appl Climatol. 99 : 187-197

Saji N H, Goswamo B N, Vinayachandran P N, Yamagata T. 1999. A Dipole Mode in the Tropical Indian Ocean. Journal of Nature. 401 : 360-363

A paper presented as the invited speaker in the $1^{\text {st }}$ International Conference on Science and Mathematics (IMC-SciMath) 2019, Parapat October 9-11, 2019. 